\title{
MIGUEL ESPINOSA: DE LA NARRATIVA POSMODERNA AL DISCURSO NEOBARROCO
}

\author{
Fernando R. DE LA FLOR
}

Universidad de Salamanca

La novela, tomada con el rigor que se debe, es una composición ingeniosísima cuyo ejemplo obliga a imitación o escarmiento.

No ha de ser simple, ni desnuda, sino mañosa y vestida de sentencias, documentos y todo lo demás que puede ministrar la pruedente fillosofía.

Suárez de Figueroa, El Pasagero.

¿Podría presentarse la obra del escritor murciano Miguel Espinosa (19261982) como un paradigma de la narrativa posmoderna? ¿Podríamos legítimamente avanzar más en el camino de esa fragmentación del concepto de modernidad y atribuir a unas obras como Tríbada (La Tríbada Falsaria, primera edición: 1980; La Tríbada Confusa, 1984) o Escuela de Mandarines (primera edición: 1974) una entidad "neobarroca"? ¿Podría ser, en fin, Miguel Espinosa autor de un discurso en alguna medida "revivalista"? La proposición no debe escandalizar, pues ha sido progresivamente anunciada ya en la percepción crítica de un Gonzalo Sobejano (1987, pág. 59), que ha visto en Escuela de Mandarines un cierto "remake" del Quijote; por José Luis Aranguren (1975; 1987, pág. 43), que ha dicho sobre la misma obra que era el Criticón de nuestros tiempos y, en fin, también por una variada serie de críticos, que, encabezados últimamente por Pablo Gil Casado (1990, pp. 334-338), han señalado siempre la extraña y constante resonancia que los clásicos del Siglo de Oro alcanzaban en la novelística de nuestro autor. De un modo más superficial, esto mismo ha sido advertido por Rafael Conte (1984), mientras que Carmen Escudero (1988, pp. 100 y ss.) ha insistido en el tema del "cervantismo" espinosiano.

No, ciertamente, no es novedoso afirmar que Miguel Espinosa se sitúa quizá en la contemporaneidad más radical, precisamente por inyectar en el presente algunas de las estrategias lingüísticas y, también, como veremos, los 
desarrollo conceptuales construidos en ese pasado, justamente denominado como áureo dentro de nuestra cultura.

Puede pensarse que la presencia de una huella barroca en la obra novelística de Espinosa no escandaliza, sino al revés, tranquiliza, pero, eso sí, sólo a todos aquellos que reducen su concepto de "barroco" a una serie de cuestiones meramente formales, y que, al hacerlo así, olvidan la dura carga ideológica que bajo este término siempre se ha ocultado. Y es que hay un "barroco para niños", como quería Ernesto Giménez Caballero (1979, pp. 23-31), en un artículo no suficientemente célebre e, incluso, un "posmoderno" explicado también "a los niños", siguiendo el recientísimo libro de Jean Francois Lyotard (1986), pero hay también un barroco - y su correspondiente neo-barroco- no apto para ser sometido a simplificaciones e ingenuidades.

Si un cierto modo de proceder barroco vuelve en nuestro días al escenario de la cultura internacional, como han señalado recientemente $\mathrm{O}$. Calabresse, acerca de lo que él denomina la "era neobarroca" (Calabresse, 1990), o Gilles Deleuze (1990), en su estudio sobre la presencia de Leibniz y la concepción física del universo barroco entre nosotros; si todo ello aparece hoy incluso reflejado en los periódicos (AAVV, 1990), y si convenimos que es en la sintaxis, en el lujo inestable de la palabra, en la complejidad de las fórmulas narrativas adoptadas, donde mejor cuaja esta categoría barroquizante del discurso -que alcanza sin duda a la obra espinosista-, no es menos cierto que "lo barroco" y su vuelta estará forzosamente cargado de otras determinaciones más "fuertes", a las que bien podemos llamar resultado de una concepción del mundo, de una ideología; en fin, incluso de una postura $-y$ he aquí la novedad-religiosa.

Vamos a la búsqueda entonces, a través de las Tríbadas y de la Escuela de Mandarines singularmente, a la búsqueda, digo, de unas condiciones endógenas por las que un cierto barroco retorna como "neo" (Hocke, 1961; D'Ors, 1966; Dubois, 1973; Buci-Glucksmann, 1984; Dorfles, 1989; AAVV, 1990 b). No la estética de las formas, sino una cierta ética de las ideas es lo que, en definitiva, buscamos cuando nos interrogamos ahora por la singularidad que estas novelas o tratados encarnan, y más allá de ellas, por lo que incluso podemos denominar el enigma espinosiano, el grado de dificultad que el texto opone al análisis superficial.

\section{La escritura y la (Contra) reforma}

Sin duda hay una cara oculta, incluso no deseada, ni sospechada siquiera en nuestro tiempo, en la producción de un signo barroco. Quienes hoy hablan de neo-barroco desde una perspectiva hispana (Sarduy, 1972; Lezama Lima, 1977, pp. 319 y ss.), hablan más de un retorno de la sociedad-espectáculo, de las estrategias de simulación, de la estética de la repetición y de la desmesura y del discurso ampuloso y vacío, culterano en definitiva, que de una dimensión 
conceptista, cerradamente doctrinal, tercamente metafísica, que abarca también, creemos - y más en el caso de Espinosa-, la producción de una obra de arte bajo este signo.

Es ello, justamente, lo que sí puede escandalizar, el señalar la Tríbada como obra en la estirpe jesuítica, en línea todavía abiertamente más ignaciana que la adoptó Joyce en su Stephen Hero, o que conforma también algunas de las peculiaridades que presenta el Ulises (R. de la Flor, 1979); en denunciar también, en Escuela de Mandarines un talante "frío y ético, voluntarista y sarmentosamente ornamental "(Sarduy, 1974, pág. 68), marca "de fábrica", diríamos también en este caso, de las grandes producciones de la Reforma católica.

Pero si queremos proceder con cierto orden, si queremos describir la existencia de una cierta retombée barroca; de un efecto de "recaída" o eco barroco en Espinosa, hay que distinguir entre un registro formal, una serie de recursos expresivos, una retórica, en definitiva, y lo que es el núcleo ideológico que anima su concepción (si es que es posible separar ambas).

En cuanto a lo primero, a los fenómenos de superficie, no me voy a entretener nada en revisarlos. El asunto fue abordado en su momento por Ignacio Soldevila (1980, pág. 114), que define la prosa espinosiana como "lenguaje clásico, mezcla de nuestros grandes autores del siglo XVII, y particularmente Cervantes, que parece tener como misión facilitar la distanciación entre el lector y el relato $y$, a la vez, darle la virtud importante de los textos sagrados". En efecto, en este orden de cosas, hay un uso desmesurado en Espinosa del oxímoron, pieza clave en la estrategia textual barroca. Junto a él, otra figura cultivada por Espinosa, singularmente en Escuela de Mandarines es la hipérbole, detrás de la cual sabemos que late la hipertrofia y su efecto inmediato a nivel de la "elocutio": la amplificación. Toda la Escuela... está montada sobre esa operación que en su propio exceso confina naturalmente con lo raro, con lo original, lo inédito, algo que sabemos Espinosa buscó siempre con fruición. Y está también la elipsis, todopoderosa en Tríbada, donde, de los dos centros insinuados - Damiana y Daniel — uno de ellos - Daniel— se da en ausencia; está obturado, excluido de la luz, juega el papel del oscuro y elidido.

La onomástica, por otro lado, sugiere en su literalidad un acercamiento efectivo a las novelas barrocas de estructura alegórica: el nombre, en Espinosa como en Gracián, está dotado de una dimensión semántica.

Y, en definitiva, es innegable que la escritura de Espinosa, en cuanto que comparte las características formales de una escritura barroca, busca la sintaxis y la disposición, pero sin contención, de modo diríamos inmoderado. Prosa sin contención, rodeada de toda serie de efectos de extrañamiento, cuya singularidad después de todo obedece a que tal vez no trata de hacerse admirar por ella misma - estamos aquí, ante estas páginas fascinantes lejos de la consigna del arte por el arte, y lejos, también, de una actuación que desemboque en un experimentalismo vacío-. No. Si la retórica despliega en Tríbada o en Es- 
cuela de Mandarines sus fastos muy lejos de la normatividad de la lengua vulgar o coloquial, es para, en definitiva, conseguir un efecto barroco más: el de potenciar hasta el límite su capacidad de persuasión: se trata en términos gracianos de conquistar la agudeza en el concepto en razón de su rareza.

Esto es, quizá, cuando cabe decir en el nivel mismo de la lengua literaria empleada por Espinosa, pero en cuanto al discurso que enmascara la ficción literaria, éste despliega una considerable cantidad de efectos barrocos que vamos a considerar de modo más detenido, sobre todo porque es, pienso, precisamente en esta dimensión ideológica que tiene todo texto, en donde, de modo más evidente, coagula en Espinosa una actitud "revivalista".

\section{Ideología y Novela}

Para comenzar una vez más desde el principio: la prosa de Espinosa ostenta un primer efecto de extrañeza, de lejanía de la norma; incluso de aversión hacia los modelos instaurados de novela; ello para enseguida también afirmar que al nivel de la ideología que la funda se sitúa frente a frente de lo que es la "doxa", es decir, frente al conjunto de opiniones y valores establecidos socialmente y acatados y respetados mayoritariamente en el momento de irrupción de la obra. Esta prosa así concebida se nos entrega pues bajo la máscara de la alineación; producto incluso que puede sospecharse como efecto de un delirio autista, de una particular fantasía de autor.

Estamos aquí ante una prototípica orgía lingüística de claro signo barroco (y toda orgía tiende a situarse en el segundo término de la polaridad establecida entre lo "clásico" y lo "anticlásico"), en donde las alusiones verbales, los juegos de homonimia, las relaciones cabalísticas, el acento puesto en Ia singularidad, la transfiguración del término por una intención inefable, los híbridos de vocabulario, el cáncer verbal del neologismo, el enviscamiento de la sintaxis, todo, nos habla — singularmente a través de Tríhada- de un sujeto enajenado en la escritura: sujeto al que es dable reconocer como quimérico o poético: es el caso de Daniel o, incluso, como sujeto real, pues no faltan precisamente las indicaciones de que es en realidad el propio autor el que se encuentra implicado de una manera existencial en el desarrollo de la trama.

Esta alineación -o alucinación-, esta enajenación casi del sujeto real en la palabra ficcional, es hoy una de las marcas del barroco, ello hasta el punto de configurar uno de los signos distintivos más claros del retorno neo-barroco, por ejemplo en el cine, con las películas de Greenway o, recientemente ente nosotros, con relatos fílmicos del calado que ostenta El sueño del mono loco.

Así que buena parte de la singularidad intelectual que le reconocemos a Espinosa, proviene indudablemente de esa operación arriesgada mediante la cual el yo -el yo de autor, el sujeto real que fue Miguel Espinosa - se implica en la escritura, se nombra así mismo dentro de ella, y con él a sus amigos y a sus amores (o tal vez deberíamos decir a "su amor") — y también, a sus enemigos, 
claro está- haciendo, en definitiva, que el texto hable elocuentemente de la estructura sicológica de quien lo ha concebido. Así el relato, como modo de narrar y de narrarse en su más noble función, se entrega como el síntoma mismo de una sicopatía, como documento de una relación infeliz del yo con el mundo.

El tex to espinosiano testimonia el mundo en la línea misma del desengaño barroco: es decir, da fe cumplida de la carencia del "logos", de la razón, aun en su mismo despliegue; de su incapacidad también probada para controlar y armonizar lo real. Patética imposibilidad, pues, de Daniel para que, a través de un proceso minucioso de racionalización del ser de Damiana, pueda volver a amarla y revivir su historia, todo ello en Tríbada; pero impotencia también paralela en el Eremita de Escuela de Mandarines, incapacidad en este caso, de que, a través de la palabra y del testimonio de la justicia y la verdad, pueda de algún modo ser abolido el reino del error y de las jerarquías representadas en la "Feliz Gobernación".

Lo propio del barroco, ha dicho José Luis Brea (1990) recientemente, es estimular un enunciado que es plenamente autoconsciente de su incapacidad para emitir sentencia desalienatoria sobre el mundo y la realidad. $O$, en otras palabras: el texto barroco presenta en grado muy agudo la conciencia puntillosa de la falla insalvable que existe entre el deseo que se expresa en la lengua y la realidad de ese mundo designado. Y aun podríamos encontrar una formulación más clara para lo que representa en su núcleo esa escritura o discurso barroco -o neo-barroco- que practica Espinosa, entendiéndola esta vez como revelación de la objetividad del mundo histórico - ese mundo histórico en donde, recordemos, algún día operó Damiana o los Mandarines-, y la evidencia paralela de su cumplido destido roto, quebrado.

Ello supone la condena - - y de aquí la novela entendida como suplicio- - a una contemplación micrológica de la sucesión y el depositarse de fragmento sobre fragmento, de ruina sobre ruina. Algo que es para todo lo humano como una suerte de destino inexorable, que la novela no quiere velar, sino, antes bien, poner patentemente de manifiesto.

"Sólo he querido describir la condición humana y la nada y miseria que somos todos, así Damiana, asi Miguel Espinosa, así yo, así tú y los hombres nacidos", se lee en Tríbada. Proyecto éste de la novela, en verdad teológico: una propuesta casi tridentina, si el término mismo no entra en contradicción flagrante con actitudes de Miguel Espinosa muy lejanas de cualquier ortodoxia.

En todo caso, en ello se muestra Espinosa el más profundamente barroco de los escritores de nuestro tiempo, por cuanto su proyecto cumple además con ese axioma que Gilles Deleuze (1990, pág. 36) ha encontrado en el fondo de la percepción barroca del mundo, que procede siempre a pulverizar el mismo mundo; es decir, a anatematizarlo y destruirlo, para, simultánemente, espiritualizar el polvo restante, redimirlo de algún modo por la vía de la nostalgia que su pérdida y su ruina provocan. Y, en este punto la observación de W. Benjamin 
sobre el fondo del drama funeral alemán en el barroco es más que pertinente al discurso espinosiano: "La melancolía barroca - escribe Benjamin - traiciona al mundo por amor al saber. Pero en su tenaz absorción contemplativa se hace cargo de las cosas muertas, a fin de salvarlas".

Damiana misma, para volver a este personaje de todos conocido en la Tríbada, que es mundo, que es demonio y carne, por serlo, es pulverizada, reducida a la nada de su actuar; pero ello, sólo para, paralelamente, exaltarla más — como sucede con la figura emblemática del catolicismo contrarreformista: la Magdalena penitente- para hacerla triunfar, justamente en lo que fue. Esta doble operacionalidad se manifiesta en esa Tríbada Falsaria, primero - especie de Magdalena en su momento cortesano-, que pasará luego a ser "confusa" -como Magdalena eremita ya-, todo como primer paso de una redención que la ha de llegar por la vía del testimonio que de sus últimos momentos darán Juan, López Martí y otros escoliastas varios.

El espíritu y la carne se configuran así como un escenario de sabor antiguo donde se desarrolla todo el movimiento dialéctico, toda la sicomaquia por la que se caracteriza esta obra maestra de la literatura espiritual que es Tríbada.

Lo propiamente neo-barroco de esta situación es ese inyectar el espíritu (una noción de cuño aristotélico, en cierto modo perdida y olvidada en la condición posmoderna) en el seno del relato, de la narración. Espíritu abiertamente manifestado en la constitución de un yo moral y de un juicio, que rebasa la instancia ficcional y que aparece como autolegitimado para valorar lo que es el mundo y lo que sea la carne y su triste destino.

Pero para utilizar una vez más esta palabra, él, el espíritu, su voz encarnada en Daniel y Juana, es quien cuestiona la carnalidad a la que se entregan Damiana y Lucía (de las que se dirá que sólo genitales y tedio las configuran); del mismo modo como ya en otro texto - Escuela de Mandarines- la conciencia vigilante del eremita cuestiona moralmente las convenciones y falsedades sobre las que monta su existencia misma la "Feliz Gobernación".

Siempre, pues, ese principio que encuentra en el cuerpo y sus derechos una animalidad y un desorden que le aturde; pero es también esa misma animalidad, esa humanidad orgánica la que le permitirá elevarse: es de este modo cómo la trayectoria del cuerpo lesbiano de Damiana es cebo para el espíritu de Daniel, que por su misma contemplación, por esa delectación morosa y morbosa con que lo mira y lo escribe, se sumerge en el pasmo, y puede llegar a forjar así ese aforismo espinosiano que es como un lema para toda la novela: "La contemplación del mal es iluminación". Contemplación en buena medida inmanente, eterna, y aquí la condición posmoderna que asume el discurso espinosiano se evidencia con fuerza al generarse en esa concepción "abierta" del comento, en esa agobiante referencialidad sexual.

No de otro modo sustancialmente diferente opera la literatura espiritual; abismada en una descripción del mal —el mundo, el demonio y la carne- de la que en rigor el espíritu no puede separarse un sólo centímetro. 


\section{El modelo clásico}

Contemplación đel mal, resucitación de la idea de pecado, aversión hacia el cuerpo desinhibido de la mujer ¿no es acaso ésta una trilogía de incitaciones que podríamos seguir sin problemas en otras novelas barrocas de inspiración contrarreformista?

En efecto, resulta, y ello ha podido pasar desapercibido, que una novela como Escuela de Mandarines se sitúa, en este orden de cosas, más que en la estela que marca el Quijote, influencia que fue señalada en su día el primero por Ramón Jiménez Madrid (1982, pág. 129, en aquella otra línea producto de una visión rígidamente moral, de lo que es un mundo conformado desde una ideología concreta y militante. Me refiero entonces a que todo acerca Escuela de Mandarines, sino al Quijote de Cervantes, al Quijote apócrifo de Avellaneda y, ya en su misma línea, más aún al Guzmán de Alfarache, pues con él comparte al menos ese "yo" escindido, que actúa y juzga lo actuado; a los Trabajos de Persiles y Segismunda o, incluso, a una novela de corte utópico como La Arcadia de Lope de Vega. Pero, sobre todo - y más que en el caso de las anteriores- es al propio modelo del Criticón al que nos remiten ciertos aspectos de la obra espinosiana, sobre todo si queremos entender el tex to de Gracián como lo que en cierto modo es: una alegoría sobre la perversión del mundo, que es entendido como cumplimiento de un alejamiento de la ley divina que el hombre lleva impresa en su código genético, pudiendo decirse que éste, el hombre, vive sólo para pervertirla, para anularla en él.

Las correspondencias que así vemos tejerse entre la obra de Espinosa y la producción barroca de factura contrarreformista, si es que puede decirse así, no cesan ahí. Ese doble plano que lucha por distanciar a la razón de la corporalidad, o, al menos, de dotar a cada una de un espacio infranqueable para la otra, lo encontramos también vigente en lo que es el sistema de representación plástica durante el siglo XVII, en el código de las artes. De esta manera, podemos decir que, al menos metafóricamente, un texto como el de Tríbada confluye en su organización y concepto con la disposición alcanzada por cuadros famosos como El entierro del Conde de Orgaz, y podemos leer así, cuadro y obra, como ha hecho recientemente Gilles Deleuze (1990, pág. 45) con el primero, como dotados ambos de un "plano bajo", donde los cuerpos (Damiana, el cadáver del Conde, Lucía...) son víctimas de su propia pesantez y las almas tropiezan, inclinándose y cayendo en los repliegues de la materia, mientras que todo el plano superior es un potente imán que los atrae, comunicándoles un vértifo, un "vértigo de lo alto" (Deleuze dixit) que, en el caso de la novela, encarna, obviamente, en el principio representado por Daniel y en la realidad espiritualizada de Juana.

De modo similar, y espero que esto no parezca un juego de correspondencias demasiado atrevido (en todo caso, la existencia de una hipótesis de neobarroco, nos autoriza a este juego de refracciones y de homologías sorprenden- 
tes, como el mismo Calabresse (1990, pág. 12), por ejemplo, ha emprendido, cuando escribe a propósito de las relaciones ente la estructura narrativa del Pato Donald y de la Divina Comedia), es posible establecer otros paralelos visuales para la obra de Espinosa. Aceptando ese principio de conexiones lejanas, también Escuela de Mandarines encuentra su correlato plástico en esas pinturas de género que abundan en la Contrarreforma y en las cuales un eremita, preferentemente San Antonio, rechaza la Mundaneidad, que adquiere mil formas, como mil formas también adopta el discurso del poder que el eremita espinosiano rechaza y desautoriza.

Esa es, en cierto modo, la tradición de la que se reclama la parte más extraña e irreductible de la obra global de Espinosa, y ello - lo comprendopuede suscitar aversión y un cierto escándalo, e incluso no digo que no me lo haya suscitado a mí.

Una cosa es ser neo-barroco por la factura de la lengua, y otra cosa es ser neo-barroco por resucitar todo tipo de fantasmas dormidos, aletargados en el inconsciente de nuestra cultura, represiva e infeliz, como tantas veces se ha dicho. Espinosa sí resucita esos cadáveres de la caverna hispana, convocándoles como destinadores nuevos en la estructura narrativa; así Dios, la moral rigurosa, la conducta eidética, la tristeza de la carne (Sobejano, 1986; Urdanibia, 1990, pág. 70).

En cuanto a sus personajes, por tantos motivos peculiares, tal el eremita, así también Daniel o Juana, ellos conforman una suerte de reverso, de "contrafactum" de aquellos que en su día abrieron la modernidad. Si las recientes generaciones han nacido en cierto modo de una lectura del Zarathustra nietzscheano bajando de su montaña para predicar entre los hombre la muerte de Dios, cerramos hoy el ciclo perplejos leyendo también cómo los personajes de Espinosa están inscritos en el relato para decir que Dios o el espíritu están vivos, que siguen juzgando. Lo que implica lo que ha sido denominado como "revuelta contemporánea contra los padres del pensamiento moderno: Descartes, Locke, Kant, Marx" (Mardones, 1990, pág. 28).

Extraña condición posmoderna ésta de Espinosa, que gusta de traer al contexto de la modernidad lo que la combate o aniquila (Casado, 1988).

Pero en esta misma estela; la verdad es que Espinosa ha tenido siempre en nuestro país - claro está- precedentes, y me parece raro que a estas alturas no hayan sido todavía señalados. Entre todos los posibles que podrían ser apuntados (entre los que quiero dejar expresamente al margen por el momento a Miró y Azorín) a mí me parece que los escenarios metafísicos que plantea Unamuno en alguna de su nívolas o novelas encuentran en Espinosa su eco, ciertamente disimulado. ¿Cómo no ver, en este sentido, una misma identidad femenina, y más, una paralela funcionalidad estructural detrás de los papeles que cumplen Juana y Angela Carballino, esta última en la novela de San Manuel Bueno Martir? En efecto, ambas son relatoras, en el sentido en que una instruye un proceso de canonización y la otra de demonificación (si puede decirse así); ambas son, 
incluso, evangelistas laicas y así, Juana, el personaje espinosiano puede decir, con palabras de su homónimo San Juan:

El mundo a mí me aborrece porque doy testimonio contra él de que sus obras son malas (San Juan, 7,7).

Las distintas posiciones en el marco del relato comportan también cierta identidad, puesto que su hablar es un hablar al mundo del hombre, una develación casi del misterio de la piedad femenina, al tiempo que como ángeles terribles y apocalípticos separan la luz de las tinieblas, nombran el nombre del pecado; recuerdan la llegada del Juicio. Ante Juana, Daniel, como, antes, Eneas frente a Dido, puede decir: Infandum, Regina, iubes renovare dolorem.

Figuras también éstas en la mejor tradición de sexualidad excéntrica: en ellas se reconcilia eros con el misticismo y la amante frustada da paso a la Madre imaginaria, a la virgen al pie de la crucifixión. ¿Y qué hay más barroco que todo esto?

Novelas teológicas - o de aprendices de teólogos-, las de Unamuno y Espinosa (como en el pasado también aspiraban en cierto modo a serlo las de Gracián y Mateo Alemán), pero, preciso es decirlo enseguida, de una teología de la negatividad, de una teología que ha de preguntarse más por la ausencia que por la presencia del proyecto divino (López Martí, 1987). Se trata, incluso, si deseamos ir más allá, de lo que los filósofos de la posmodernidad, como Gianni Vattimo, denominan una "ontología negativa", designada como la tarea (de los héroes) de nuestro tiempo (Vattimo, 1990; Savater, 1991), análisis del ser, no ya en su progreso hacia la total plenitud, sino, antes bien, en el progresivo disolverse de su naturaleza, hasta su completa extinción.

Las novelas mayores de Espinosa deconstruyen así, decapan (ello en varios sentidos) el ser de su protagonista, hasta llegar a una suerte de entidad cero. La vieja mirada metafísica en el pasado elevaba al ser por encima de la naturaleza caída, la nueva visión fenomenológica lo reduce, en cambio, a su no nada, incluso a su no-ser (Vattimo, 1987).

Tríbada, dado que explora el acontecimiento nimio, se presenta como revelación universal de la nada sobre la que se sustenta el mismo mundo, el demonio, el deseo y la carne.

Lo que a estos efectos se ha achacado siempre a Miguel de Unamuno valdría también para definir la especificidad en la que se mueve la práctica narrativa de Miguel de Espinosa: la sólida encarnadura ideológica, el lastre conceptual, la pesada carga de las ideas hipertrofia siempre el camino del relato, el comento finalmente, que deviene indefectiblemente monstruoso con relación a lo escaso de la anécdota. Es ésta, también, la manera de darse una producción barroca, habitada siempre por un significado complejo, por una trama ideológica que excede su soporte. Como sucede en esos emblemas que circularon profusamente en el época, en el siglo XVII, donde una pequeña imagen - una corona, un manzano, quizá un gesto humano-, suscita un 
ingente comentario moral que se apoya en las Escrituras y dota de una realidad simbólica el mundo de las apariencias. Así, en Espinosa, un gesto sin alma de Damiana, por ejemplo al volante de su coche o transportando un paquete o mirando a su "garzona", suscita el comentario interminable de los autores de la Escuela de Murcia, lo que concede al triste hecho una dimensión trascendental, cuasi religiosa.

Por todo, pues, esta producción es una escritura barroca que se sitúa en un espacio axiológico quimérico, soñado. Espacio propio que nace para asegurar frente a la hemorragia de la realidad la existencia de un sistema de valores, de una estructura, desde la que es posible enfocar un cierto mundo. En ella, es palpable la exhibición, el orgullo, la hibris (para hablar en los términos clásicos que tanto gustaban al escritor murciano) de los principios, una hibris propia de los principios. Esta existencia de una estructura moral, de una red de valores, es la que confiere en toda su estatura de papel de sujetos y jueces a los personajes de Daniel o el Eremita, y, más allá de ellos mismos, pensamos que es en nombre de esta borrachera de los principios bajo la que debió actuar muchas veces en su vida privada M.E., soberbio siempre frente al mal, que para el encarnó el pensamiento burgués, la "fea burguesía" (La fea burguesía, primera edición, 1990).

De modo que en Espinosa también encarna, por este lado, una cuestión barroca recogida en sus ecos, en sus sucesivos "revivals" y comparecencias, producidas en el aquí y allá de nuestras letras. Puede que el pesimismo jesuítico frente al mundo de un Gracián fuera su guía para una cierta visión que de la realidad quería transmitir, pero su herencia es más pesada y vasta y, en general, abarca toda la escritura metafísica - o simplemente doctrinal en su versión teológica o fenomenológica-, y ello en cualquier género en donde ésta se ha ido produciendo, desde el siglo XVII a nuestra contemporaneidad.

No hay pues reparo en afirmar aquí, por más que el concepto se encuentre en derribo, que sea la de la metafísica la operación intelectual que más directamente nos introduce en una obra que el mismo Espinosa no dudó en definir, sin ironía, como auténticos "tratados que exploran las causas últimas". Ha sido Claude-Gilbert Dubois (1980, pág. 78) quien ha dicho que el barroco "afirma una manera de sentir las relaciones del hombre con el mundo según un modo metafisico".

Ante el ejemplo que nos suministra Tríbada, tanto la "Falsaria" como la "Confusa", ¿quién podrá negar que su novedad, radical entre nosotros, depende justamente de ese "modo metafísico", bajo cuyo sistema está narrada una historia de sexualidad homófila? (Alonso, 1981; Araguren, 1981).

La Tríbada Falsaria se abre con la constatación de Damiana: "No creo en Dios", dice la amante de un cierto Daniel y, a partir de ese momento, se entrega a una pasión lesbiana, a "una gana de la vulva", como dice Miguel Espinosa, que va a ser implacablemente diseccionada por los amigos de Daniel, interesados en hacer, como ellos mismos explicitan, "ciencia del hecho fricativo" (Ferrand, 1983). 
El suceso, tal y como es presentado, no está exento de implicaciones sicoanalíticas. Estamos ante la descripción de una máquina deseante y de su inserción en el imaginario de otra máquina; del fracaso final de este acoplamiento, complejo, en el caso lesbiano. El texto en este sentido se hace cargo del peligro que la relación narcisista y especular entraña. De esta profunda manera Miguel Espinosa desvela la relación homófila, resultando particularmente infundada y gratuita la observación de Andrés Salom (1981), cuando afirma: "La Tríbada Falsaria es una novela de concepción pequeño burguesa, entre otras muchas razones, porque aborda aisladamente el problema del que pretende ser análisis -la sodomía-- con olvido absoluto de sus determinantes y condicionamientos".

Digamos que, en una primera lectura, Juana y la "Escuela de Murcia" actúan como terapeutas y científicos que, poseídos por una "libido sciendi" -una pasión de saber e interpretar- analizan la estructura temporal del deseo en la lesbiana ya madura, para racionalizarla ante su ex-amante destrozado. Podríamos decir que ello conforma una ilustración del axioma de Gracián en boca de Andrenio: "el hombre no es el rey del mundo, sino el esclavo de la mujer". Pero, a partir de esta voluntad de objetivizar cuanto de deseo y de voluptosidad hay en una vida, se desarrolla un segundo escenario, que es, por lo demás, el virtualmente original y novedoso para nuestro gusto. Los científicos de la conducta, los analistas severos - Juana, el propio Daniel... - se tornan súbitamente en juzgadores del hecho desde una dimensión metafísica; de enfermos imaginarios pasan a ser severos moralistas en activo, y aquí lo que registran ya, como aquellos primitivos teólogos del siglo XVII, es la presencia cancerosa del mal en un mundo del que Dios ha sido retirado.

El procedimiento no por radical y nuevo carece, como hemos visto, de precedentes. Esta indagación que urga en la realidad y la confronta con un plano metafísico es la base misma del procedimiento de análisis jesuítico, de la técnica de instrospección que inaugura San Ignacio.

Estamos ante lo que es una reversión del "ejercicio espiritual" ignaciano, donde, recordémoslo, una conciencia, al final del día, hace pasar sus acciones más nimias por un severo tribunal que las enmarca en un contexto intemporal, soteriológico, donde se ven enfrentadas, en su falta de sustancia, con la muerte, con el Juicio, con la eternidad. El sujeto cumple así su travesía, analiza in vitro sus acciones, se eleva, y ello por medio de una dolorosísima ascesis que contrasta su ser con la nada: “"Has imaginado — le escribe Juana a Danielcómo será el intestino hastiado con sus tripas de la gregaria?"

Técnica la del ejercicio espiritual que requiere además de dos instancias en dialéctica: una es el confesor, el maestro, el conocedor de los resortes teológicos, éste está más allá, representa la ley moral, el orden: es Daniel de la Tríbada y detrás, el Espinosa que conoce el trasfondo real de la historia murciana que cuenta. En algún lugar, el escritor ha dejado deslizar una afirmación que ya no nos puede sorprender, desde el razonamiento que estamos tratando en poner en pie: él -Espinosa quiero decir- habría escrito esta 
novela para una Daminana real, para que por medio de su lectura pudiera reformar su ser y su conducta. Ejercicio ignaciano completo, pues, catequesis y soteriología - un saber sobre la salvación, en definitiva - esto que lleva a la escritura Miguel Espinosa, donde se desdibujan los territorios de la ficción y de la realidad.

Conducir al extremo ese análisis, he ahí la novedad rigurosa que encarna la obra en el contexto de nuestras letras actuales (ciertamente un tanto desvitalizadas). Escribir y analizar, incluso desde el mañana, dando todo como fatalmente cumplido, he ahí la visión teológica, y la novedad, juntamente, en este manejo del tiempo narrativo; resultado de lo que llamaba el propio Miguel Espinosa: "proceso de extrañamiento hasta todo límite" (Precioso, 1980; Miralles, 1981). Revisión, pues, metódica del suceso, hasta contemplarlo con pasmo y, más allá, como un poco póstumo y cumplido.

El trabajar por descubrir en la estructura íntima del deseo su falta de vocación de permanencia; el rechazo de la "voluptas" y de la concupsicencia y la constancia del terror y el vacío que se esconde detrás de las estrategias de seducción, nos acerca aún más, si cabe, a un núcleo de pensamiento que estuvo activo antes de su liquidación definitiva por la Ilustración y sus nuevos ideales fundados en el cuerpo y sus derechos inalienables. Supuesto que Espinosa opere con estos valores, ello nos aproxima, aún más, si cabe, a un escenario barroco, en donde otros efectos nos aguardan para dar cuenta de ellos.

El primero, en orden de importancia, que trasluce en la Tríbada es la cuestión misógina. El terna está envenenado, y yo no querría contribuir aquí a hechar leña a ese fuego. Ya en su momento, Aranguren vio clarividentemente lo que en términos de hoy podría ser tomado por militancia antifeminista de Miguel Espinosa. Y ¿qué decir en este sentido que pudiera valer de ingenua defensa de un hombre que ha dejado escrito la radicalidad de su juicio en este tema a través de entrevistas, sobre todo, donde ha podido llegar a afirmar, por ejemplo, que una actriz le parece un detritus producido por el nihilismo burgués, que simula el coito para que sea filmado y luego se vea en el cine mediante el pago de trescientas pesetas? (García Martínez, 1978).

No se trata ahora, pues, de precisar en qué sentido funciona esa misoginia espinosiana, tampoco de edulcorar o justificar esa categoría del pensamiento de nuestro autor; brevemente quisiera sólo detenerme en ese tratamiento de la instancia femenina, en, por ejemplo, Tríbada - para señalar en él una homología - ¡de nuevo una más! - con ciertas emergencias de lo femenino, de la cuestión femenina, en el texto antiguo, en el discurso "Antiguo Régimen".

"Veis esas mujeres que pasan tan prendidas de libres y tan compuestas de disolutas? Pues esas son las verdades sirenas y falsas hembras, con sus fines monstruosos y amargos dejos".

Esto que dejó dicho Gracián en las puertas de su momumento misógino El Criticón, pudo decirlo, lo dice, lo escribe Espinosa en su Tríbada que encarna a estos efectos una teoría de la culpa y de la caída del principio femenino. 
Pero la operación es más sutil si cabe, porque no sólo hay Lucías y Damianas, sino que existen también Azenaina y Juana, como antaño para Cervantes, otro misógino en lectura superficial, hubo Aldonzas junto a Dulcineas, y como para Gracián coexisten en el mismo mundo las Falimundas terribles y las Circes embrujadoras con las Virtelias piadosísimas.

Esta escisión, apenas oculta y disimulada, que es practicada sobre el mundo femenino, es también la característica en el discurso barroco emitido por una instancia masculina todopoderosa y falocrática que gusta de condenar el cuerpo objeto de pecado, mientras salva un alma quimérica, un principio ideal de lo femenino que coagula a menudo como "Madre", como "Virgen" también.

En nombre de una superdiosa ideal, Filis de la novela pastoril; Dulcinea, de la cervantina, Juana, de la espinosiana, se condenan las emergencias físicas de la mujer real: Maritornes o Damiana. Así el sujeto masculino, si deseamos una lectura sicologista, obtura su contacto con la mujer en minúscula, en nombre de su aspiración a la superwoman.

Y así se aleja, también, el peligro de este acto simbólico que es la cópula, tabuizada absolutamente en Tríbada y acto que resulta prohibido en Escuela para los rebeldes al hecho. Aquí, en este punto de nuestro argumento, Don Quijote, Andrenio y Critilo se unen a Daniel y al Eremita, todos ellos - como díríamos con un sintagma espinosiano- "enemigos de la vulva", entendida a menudo en estas obras como "vagina dentada", como monstruo y quimera del amor, como órgano de devastación de una especie de mantis religiosa que representaba a la mujer en su deseo desordenado.

Se trata, en todo caso, de cercar la alteridad, esa hemorragia por la cual el otro deviene siempre extranjero. Alteridad absoluta del hombre, la mujer; del heterosexual, el homosexual; del ser de pensamiento, el ser de acción. Esta cuestión, que recorre el texto espinosiano es un efecto barroco más, un efecto "Antiguo Régimen", si se puede hablar así, pues es sólo con la modernidad cuando se sutura ese espacio, tiende a cerrarse esa herida y se abre un período de reconciliación, de admisión, de tolerancia interpersonal o intersexual, o, al menos, eso nos parece (África Vidal, 1990, pág. 58).

Pero en este tema de la mujer, hay un pasaje en la obra espinosiana que siempre me ha impresionado y que denuncia la existencia de una concepción de lo femenino radical, basa y sustento — pero también pérdida y sujeción-con respecto a ese mundo macho que encarna el pensar.

Me refiero a esa referencia, verdaderamente extemporánea, alucinatoria diríamos, referencia a la muerte de la madre, que irrumpe, saltando toda convención, en la estructura narrativa del Asklepios. Quiero recordar aquí que Miguel Espinosa dijo allí - y quizá esto le redima de cualquier otro juicio apresurado sobre estas cuestiones - en homenaje a la madre, que con ella, con su muerte en 1972, había muerto para siempre en él, no sólo el niño que con ella había sido, sino también el joven y, más allá de ellos, hasta el hombre mismo 
que Miguel Espinosa era por aquellos años. Realmente no es fácil encontrar en nuestra lengua un tributo similar al principio de lo femenino, siquiera sea reducido a su condición fundante de "mater".

"Nunca más veré una patria ni oiré una risa. Nunca más la nube, la piedra, la planta el animal ni la cosa demostrarán novedad. Nunca más elegiré la palabra y su notación. Nunca más sentiré, ni por los ojos de alguien, la continuidad y la representación de los tuyos en los mios. Nunca más habrá candor ni donaire, inclinación hacia la Verdad ni voluntad de reflexión. Porque nada regresa, sino que transcurre sin retorno hacia la nada. Contigo muere el niño, y el muchacho y el hombre".

\section{"Porque descubría países nunca andados, regiones nunca vistas... los paí- ses del tener y del poder, con el dilatado reino de la fortuna y el mando" (El Criticón, II, 2)}

Fuera de Tríbada y de su cuestión feminista, queda todavía ese texto desmesurado (barrocamente desmesurado) que es la Escuela de Mandarines, para perseguir todavía en él las huellas de una operacionalidad, de un modo barroco de concebir los discursos y la escritura.

No me detendré ya nada en reivindicar una categoría en esta línea para la obra poliforme en la que sería, por cierto, reiterativo descubrir una maquinaria moral actuando. El propio Espinosa ha dicho que Escuela de Mandarines es una "utopía negativa del fascismo español", que trata, en definitiva de anatemizar, de exorcizar, incluso, el "ser inmoral del fascismo" (Escapa, 1984). La estructura alegórica de la que está dotada la novela, la acerca entonces a ese plan de las novelas alegóricas barrocas que tiene su modelo en El Criticón: su propósito claro es condenar la realidad histórica del hombre (el fracaso en que incurre su proyecto de ser) y diseñar en negativo una utopía de superación. Critilo recorre el mundo enjuiciándolo en lo que constituye su perversidad, y el Eremita se pone también a la escucha de ese mal y de esa perversión que caracteriza el mundo y sus obras.

No es difícil hallar en el seno de la alegoría gracianesca ese referente moral que fue la Corte, la política de Felipe IV, las camarillas de poder, los aristócratas o la propia orden de jesuitas, de la que Gracián fue paradójico enemigo. De igual modo esta otra alegoría, la espinosiana, permite resituar el universo de los estratos podridos de la sociedad franquista; la mentira, el cinismo, la impiedad, también, sobre la que fundaron su estatus social privilegiado...

Por encima de este artificio alegórico, tan barroco en sí mismo, me gustaría ahora reparar por último en la figura central que convoca el relato de Espinosa. Figura en Escuela de Mandarines - la del Eremita, la del peregrino- cuya misma emergencia no puede dejar de sorprender, pues es, en sí misma, desconocida o inaudita si la pensamos desde la modernidad. Ya había- 
mos dicho como lo propio del procedimiento narrativo de Espinosa era, en cierto modo, instalar en el centro de unas preocupaciones actuales, unos valores de los cuales se tenía perdida toda conciencia. Por eso resulta nuestro autor en numerosas ocasiones neo-griego, pero también podríamos decir neoescolástico, neo-estoico... neo-barroco, finalmente; por eso se instala con fuerza y con arraigo en un tiempo como el nuestro, cuya filosofía, cuya literatura y arte se encuentra afectado por una incapacidad de reproyección y vuelve entonces a pensar su propia historia.

Volviendo entonces al Eremita, Avalle-Arce (1985, pág. 24) analizando la novela cervantina del Persiles, ha escrito que hay tres modelos de conducta, tres personajes del relato tradicional vinculado a tres momentos históricos: el caballero en la Edad Media; el cortesano, en el Renacimiento y, finalmente, el peregrino en la Reforma Católica.

En efecto, el peregrino y su versión extrema, el Eremita constituyen un arquetipo literario - también un arquetipo artístico a través de San Jerónimo, de Juan Bautista y los Padres del desierto-, un arquetipo literario específico pues del arte y la literatura de la Reforma. No hay, es obvio decirlo, peregrinos ni eremitas ya que emprendan su camino, su ascesis de conocimiento en la novela burguesa moderna.

Los antecedentes rigurosos para nuestra novela $-\mathrm{y}$ los señalo porque perseguimos esa huella barroca en esta escritura, por tantos conceptos tan acutal - no son otros pues, que el Rutilio del Persiles; el Andremio y Critilo, de Gracián, el propio Quijote peregrino e, incluso, el protagonista de las Soledades de Góngora. De ellos se reclama heredero el eremita espinosiano, cuya figura, además, enuncia la radicalidad y el límite mismo en el que se desea vivir.

Paul Virilio (1989) - y con esto concluimos la exploración por el espacio posmoderno al que se abre la escritura de M.E.- ha puesto en evidencia, muy recientemente la existencia en nuestra época de un pensamiento de renuncia al mundo, de fobia a lo real y de actitudes de soledad y autonomía extremas. La modernidad vuelve a reconocer ahora esas viejas figuras de exigencia radical que son el monje, el eremita, el ermitaño. Paul Virilio ha hablado también de los nuevos intelectuales como de esos ermitaños tecnológicos y del desierto y del mar solitarios como de una aspiración moderna, donde se extingue para siempre el perverso murmullo de lo real.

Quisiéramos reconocer también al propio Espinosa como uno de estos peregrinos del futuro, ermitaños tecnológicos, monje, después de todo, en su "scriptorium" murciano (Sánchez Rosillo, 1987; Morodo, 1989; Jiménez Madrid, 1990; Puente, 1990), donde se ocupó infatigablemente de relatar el mal del mundo en nombrar en la carne la ausencia de Dios, en develar la existencia de un principio satánico que imposibilita la justicia y la felicidad.

¿Bastaría lo hasta aquí dicho para asegurar una ascendencia barroca neo-barroca - al discurso novelístico de Miguel Espinosa? Pienso que tal vez 
sí, al menos, no podrá negarse que este hipotético espacio ideológico de signo barroco que he diseñado en sus líneas más superficiales parece después de todo más firme que esas inexpecíficas referencias que constantemente hoy se prodigan sobre el ser "barroco" de ciertas obras de nuestro tiempo.

Frente a esas mismas obras de las que se predica un barroquismo en orden a su florituras verbales, a un vocabulario exótico o a unas referencias clasicistas y enrevesadas, Espinosa, "señor del idioma" (Tierno Galván, 1987), sin rechazar todos estos artificios retoma más seriamente cierta entraña compleja y paranoica que conforma, esta vez sí, un fondo barroco, presente siempre en nuestra cultura (R. de la Flor, 1991).

Concepto trans-histórico, pues, este de "barroco", en torno al cual parecen coagular algunas de las mejores obras de nuestra lengua. Entre ellas brillan y brillarán para siempre las perlas irregulares de las Tríbadas, y de su misma compañía emergen también imponentes frente a nosotros las potentes masas lingüísticas - los "berruecos barrocos"- de Escuela de Mandarines.

\section{BIBLIOGRAFÍA}

AAVV. 1990 a. "Temas de nuestra época. El furor barroco", El País, 26-IV-1990.

AAVV. 1990 b. El Barroco y su doble. Ciclo de Conferencias Círculo de Bellas Artes de Madrid, 30, 31-V-1990.

ÁFRICA VIDAL, María del Carmen. 1990. Hacia una patafísica de la esperanza, Alicante, Universidad.

ALONSO, Cecilio. 1981. "Una novela sobre lesbianas, una mostración estética y una meditación filosófica", Camp de l'Arpa, $\mathrm{n}^{2}$ 87, pp. 51-53.

ARANGUREN, José Luis. 1975. "Un Criticón para nuestro tiempo", La Vanguardia, 30VII-1975; publicado también en Informaciones. Suplemento n² 368, 31-VII-1975.

— 1981. "Una novela teológico-lingüística sobre el lesbianismo", El País, 1-III-1981.

— 1987. "Sobre Miguel Espinosa y su obra", Postdata, 4, pp. 41043.

AVALLE ARCE, Juan Bautista. 1985. Introducción a Miguel de Cervantes. Los trabajos de Persiles y Segismunda, Madrid, Clásicos Castalia.

BENJAMIN, Walter. 1990. El origen del drama barroco alemán, Madrid, Taurus.

BREA, José Luis. 1990. “¿Un arte neo-barroco?”, El País, 28-IV-1990.

BUCI-GLUCKSMANN, Christine. 1984. La raison baroque, París, Editions Galilée.

CALABRESSE, Omar. 1990. La era neo-barroca, Madrid, Cátedra.

CONTE, Rafael. 1984. "Miguel Espinosa o los rastos del genio", El País, 15-IV-1984.

DELEUZE, Gilles. 1990. El pliegue. Leibniz y el barroco, Madrid, Paidos.

DORFLES, Gillo, 1990. Elogio de la disarmonía, Barcelona, Lumen.

D'ORS, Eugenio. 1966. Lo barroco, Madrid, Plaza y Janés. 
DUBOIS, Claude-Gilbert. 1973. Le Baroque. Profundeurs de l' apparence, París, Larousse. - 1976. El Manierismo, Barcelona, Península.

ESCUDERO MARTÍNEZ, Carmen. 1989. La literatura analítica de Miguel Espinosa, Murcia, Conserjería de Cultura.

ESCAPA, Ernesto. 1975. "Escuela de Mandarines, utopía satírica", Reseña, pág. 28.

FERRAND, Manuel Ignacio. 1983. "La Tríbada Falsaria. Un tractatus lingüístico-religioso", Nuevo Alor, $\mathrm{n}^{\circ}$ 1, pp. 23-25.

GARCÍA MARTÍNEZ, José. 1978. “QQuién es Miguel Espinosa?”. La Verdad de Murcia, 30-VII-1978.

GIL CASADO, Pablo. 1988. "La paradoja de Miguel Espinosa: posmodernidad contra posmodernidad", Cuadernos del Norte, $\mathrm{n}^{\mathrm{0}}$ 51, pp. 58-61.

- 1990. La novela deshumanizada española (1958-1988), Madrid, Antrophos, pp. 334-338.

GIMÉNEZ CABALLERO, Ernesto. 1979. "El Barroco explicado a los niños", Diwan, 5/ 6, pp. 23-31.

HOCKE, Rene. 1961. El manierismo en el arte, Madrid, Guadarrama.

JIMÉNEZ MADRID, Ramón, 1982. Novelistas murcianos actuales, Murcia, Academia Alfonso X El Sabio, pp. 129-146.

— 1990. "Miguel, el Eremita", El Sol, 1-X-1990.

LEZAMA LIMA, José. 1977. "La curiosidad barroca", en Obras Completas, México, Aguilar, pp. 313-338.

LÓPEZ MARTí, José. 1987. "El mundo como destrucción", Postdata, n 4, pp. 69-71.

LYOTARD, Francois. 1986. Le postmoderne expliqué aux enfants, París, Editions Galilée.

MARDONES, José María. 1990. "El conservadurismo de los posmodernos", en Gianni Vattimo et alt. En torno a la posmodernidad, Barcelona, Antrhophos, pp. 21-40.

MORODO, Raúl. 1989. “Espinosa, exiliado interior”, El País, 13-VII-1989.

PAZ, Octavio. 1969. "Piras, mausoleos y sagrarios", en Conjunciones y disyunciones, México, Joaquín Mortiz, pp. 32-48.

PRECIOSO, Juan Luis. 1980. "La escritura extrañada", Línea, 14-IX-1980.

PUENTE, Antonio. 1990. "La modernidad y un señor de Murcia", El Sol, 1-X-1990.

R. DE LA FLOR, Fernando. 1979. "James Joyce y la Compañía de Jesús”, Insula, n 389, pp. 1 y 27.

- 1991. "El pasado en el presente. La España (neo) barroca", en La Spagna di oggi:modernità e conservaziones. Convegno Internazionale, Milán, Università.

SALOM, Andrés. 1981. "De mimetismo clásico al confusionismo ideológico", El Rotativo Cultural, $2^{-1}$ quincena-II-1981, pág. 8.

SÁNCHEZ ROSILLO, Eloy. 1987. "El Eremita (In memoriam Miguel Espinosa)", Postdata, $\mathrm{n}^{2} 4$, pág. 54. 
SARDUY, Severo. 1972. "El barroco y el neo-barroco", en César Fernández Moreno (coord.), América Latina en su literatura, México, Unesco/Siglo XXI, pp. 167172.

- 1974. Barroco, Buenos Aires, Editora Sudamericana.

SAVATER, Fernando. 1991. Ética a Mario, Madrid, Paidos.

SOBEJANO, Gonzalo. 1986. "Razón y canto de la edades idas", Insula, n" 472, pág. 25.

- 1987. "Comento de comentos", Postdata, 4, 1987, pp. 57-63; recogido en Introducción a Tríbada. Theologiae Tractatus, Murcia, Editora Regional, 1987, pp. I-XXVI.

SOLDEVILA, Ignacio. 1980. La novela española desde 1936, Madrid, Alhambra.

TIERNO GALVÁN, Enrique. 1987. "Señores del idioma, señores de la realidad", Quimera, n⿳0 64, pp. 47-48.

URBANIBIA, Iñaki. 1990. "Lo narrativo en la posmodernidad", en Gianni Vattimo et alt. En torno a la posmodernidad, Antrophos, Barcelona, pp. 477.

VATTIMO, Gianni. 1987. El fin de la modernidad, Barcelona, Gedisa.

- 1990. La sociedad transparente, Barcelona, Ariel.

VIRILIO, Paul. 1989. Estética de la desaparición, Madrid, Cátedra.

VIDAL, Juan Carlos. 1990. "En torno a Miguel Espinosa", La Opinión, 31-X-1990.

\section{Obras de Miguel Espinosa:}

Escuela de Mandarines. Los libros de la Frontera, Col. "Papeles Literarios", nº 7, Barcelona, 1974; $2^{\mathrm{a}}$ edición, 1983; 3" edición, 1983; 4" edición, 1987.

Tríbada. Theologiae Tractauts ( $1^{\text {an }}$ edic. en dos volúmenes, con los títulos de La Tríbada Falsaria, Los Libros de la Frontera. Col. "Papeles Literarios" n" 1, Barcelona, 1980, y La Tríbada Confusa, Los Libros de la Frontera, Col. "Papeles Literarios" $n^{\mathrm{O}}$ 5, Barcelona, 1984), $2^{\mathrm{a}}$ edic. Editora Regional de Murcia, Col. "Textos de alcance", n"18, Murcia, 1987. Introducción de Gonzalo Sobejano titulada "Comento de comentos". 